\title{
DISPENSAS DAS AULAS DE EDUCAÇÃO FíSICA: APONTANDO CAMINHOS PARA MINIMIZAR OS EFEITOS DA ARCAICA LEGISLAÇÃO
}

\author{
Osmar Moreira de Souza Júnior \\ Universidade Federal de São Carlos, São Paulo, Brasil.
}

\section{Suraya Cristina Darido}

Universidade Estadual Paulista “Júlio de Mesquita Filho", Rio Claro, São Paulo, Brasil.

\begin{abstract}
Resumo
O presente estudo tem como objetivo apresentar uma proposta baseada em um estudo de caso desenvolvido em uma escola particular, apontando algumas alternativas para lidar com o dispositivo legal que legitima as dispensas nas aulas de Educação Física. Os resultados do estudo mostram como a adoção de um programa de avaliações aos alunos dispensados da Educação Física e outras medidas tornaram-se efetivas para a diminuição desta prática. Os dados indicam que, em um estágio crítico, as dispensas chegaram a atingir 48,8\% do total de alunos do Ensino Médio e, com a adoção do programa, este percentual reduziu para apenas $2,7 \%$. Conclui-se que, apesar da legislação, é possível a construção de mecanismos que minimizem as dispensas nas aulas de Educação Física.

Palavras-chave: Educação Física - Escola - Dispensas - Legislação.
\end{abstract}

\section{Introdução}

Gaçamos uma breve reflexão a partir de duas questões para a contextualização do tema a ser discutido no presente estudo. Você já foi dispensado ou já conheceu alguém que já foi dispensado das aulas de Educação Física na escola? Você já foi dispensado ou já conheceu alguém que foi dispensado das aulas de alguma outra disciplina (qualquer outra que não seja a Educação Física) em toda a sua vida escolar?

Apesar de não podermos estabelecer algum tipo de interatividade por meio de um artigo científico, que permitisse realizarmos uma espécie de enquete sobre o tema, não é difícil inferirmos que a resposta à primeira questão é afirmativa e à segunda é negativa, talvez salvo raríssimas exceções.

De acordo com Tardif e Lessard (2007), a escola tradicional se dirige antes de tudo à "cabeça" dos alunos e, segundo Vigarello (1978 apud TARDIF; LESSARD, 2007), é justamente por este motivo que a Educação Física, na medida em que tem o corpo por objeto de práticas escolares, sempre teve um papel ambíguo, a maior parte do tempo com o objetivo de controlar este corpo.

Apesar da necessidade de relativizarmos o dualismo cartesiano presente na citação anterior, temos ciência de que pode indicar a imagem comumente assumida em relação ao papel da Educação Física na escola.

Essa reflexão nos leva a assumir que o status da Educação Física no contexto escolar não se equipara ao das demais disciplinas e este pressuposto pode ser enten- 
dido como o foco da inquietação que nos levou a investigar a questão das dispensas nessas aulas. Assim, os objetivos desse estudo consistem em investigar a trajetória dos pedidos de dispensa nas aulas de Educação Física no Ensino Médio em uma escola particular e apontar algumas possibilidades pedagógicas possíveis no sentido de minimizar esta prática, desenvolvidas neste mesmo colégio.

Do ponto de vista dos procedimentos técnicos metodológicos, a pesquisa baseouse no estudo de caso, que consiste na análise de um caso, bem delimitado, cujo interesse incide naquilo que ele tem de único, mesmo que apresente características que possam ser comparadas com outros casos eventualmente (LÜDKE; ANDRÉ, 1986).

De acordo com Lüdke e André (1986), o estudo de caso qualitativo fornece um grande potencial para o conhecimento e para a compreensão dos problemas da escola, pois, ao retratar o cotidiano escolar em toda a sua riqueza, esse tipo de pesquisa proporciona elementos preciosos para uma melhor compreensão do papel da escola na sociedade.

O estudo de caso foi abordado por meio da análise do processo de implementação de ações para reduzir o número de alunos dispensados da Educação Física no Ensino Médio em uma escola particular do município de Rio Claro. Os dados foram levantados junto aos docentes de Educação Física do colégio e por meio dos registros e experiências vivenciadas pelo pesquisador do estudo que foi professor nesta escola durante 11 anos e coordenador de Educação Física por 4 anos, participando efetivamente de todo este processo.

\section{A educação física na legislação brasileira}

Na primeira Lei de Diretrizes e Bases da Educação Nacional - Lei no 4024 de 20 de dezembro de 1961 - a Educação Física é contemplada no artigo 22, cujo texto é redigido da seguinte forma: "Será obrigatória a prática da educação física nos cursos primário e médio até a idade de 18 anos” (BRASIL, 1961).

O caráter da Educação Física presente nesta legislação estava diretamente relacionado à capacitação física do aluno, visando formar o futuro trabalhador que seria fundamental para o processo de industrialização vivido pelo país naquele período. A própria limitação com relação aos 18 anos de idade indica uma interrupção da necessidade da Educação Física e, consequentemente, de exercícios físicos que causariam desgaste ou exaustão, no período em que os indivíduos, supostamente, necessitariam de um maior aporte energético em função de sua inserção no mercado de trabalho.

A LDB é revista com a reforma educacional proposta 10 anos depois de sua criação, por meio da Lei no 5692 de 11 de agosto de 1971 (BRASIL, 1971). De acordo com Castellani Filho (1997), esta lei deixa de fazer referência ao limite de idade da prática da Educação Física, optando por regulamentar a questão por outro mecanismo, que é posto em prática naquele mesmo ano, pela promulgação do Decreto $\mathrm{n}^{\circ} 69450$ de $1^{\circ}$ de novembro, que aludia nos quatro incisos de seu artigo $6^{0}$ às condições que facultavam ao aluno a prática da Educação Física, com base na seguinte redação: 
Decreto no 69450, Artigo 6 - "Em qualquer nível de todos os sistemas de ensino, é facultativa a participação nas atividades físicas programadas: a) aos alunos do curso noturno que comprovarem, mediante carteira profissional ou funcional, devidamente assinada, exercer emprego remunerado em jornada igual ou superior a seis horas; b) aos alunos maiores de 30 anos de idade; c) aos alunos que estiverem prestando serviço militar na tropa; d) aos alunos amparados pelo Decreto-lei 1044 de 21 de outubro de 1969, mediante laudo do médico assistente do estabelecimento." (CASTELLANI FILHO, 1997, p. 21).

Segundo Castellani Filho (1997), a facultatividade da Educação Física aos alunos do período noturno que comprovassem vínculo empregatício logo foi estendida aos alunos do turno diurno, fato que acabava por reforçar a lógica de que, estando o aluno já integrado ao mercado de trabalho, não caberia mais à escola, mas sim ao próprio mercado, a responsabilidade pela capacitação e manutenção de sua força de trabalho.

Segundo o autor, seis anos mais tarde outras duas alíneas foram anexadas a estas quatro, dispensando das aulas de Educação Física os alunos que frequentassem os cursos de pós-graduação - reforçando a tese de que a Educação Física não guarda qualquer tipo de relação com "atividades intelectuais" - e uma última alínea que facultava, à mulher que tivesse prole, a prática da Educação Física, legitimando o pressuposto de que a criação dos filhos caberia exclusivamente à mulher, enquanto ao homem caberia a responsabilidade de prover o sustento do lar.

Além de tudo isso, de acordo com Silva e Venâncio (2005), a essa época a Educação Física era considerada uma mera atividade extracurricular, não sendo, portanto, identificada como parte integrante do currículo escolar como uma disciplina acadêmica.

A Lei de Diretrizes e Bases da Educação Nacional aprovada em 17 de dezembro de 1996 (LDB - 9394/96), trouxe em seu texto, referente à Educação Física, a seguinte redação em seu artigo 26, parágrafo $3^{\circ}$ : "A educação física, integrada à proposta pedagógica da escola, é componente curricular da Educação Básica, ajustandose às faixas etárias e às condições da população escolar, sendo facultativa nos cursos noturnos" (BRASIL, 1996).

Segundo Silva e Venâncio (2005), a promulgação desta lei muda o status da Educação Física que passa a ser considerada um componente curricular como outro qualquer. Os avanços proporcionados por esta nova redação do texto da lei podem ser compreendidos pela definição de componente curricular proposta por Souza Júnior (2001, p. 83):

[...] não apenas um constituinte do rol de disciplinas escolares, mas um elemento da organização curricular da escola que, em sua especificidade de conteúdos, traz uma seleção de conhecimentos que, organizados e sistematizados, devem proporcionar ao aluno uma reflexão acerca de uma dimensão da cultura e que, aliado a outros elementos dessa organização curricular, visa a contribuir com a formação cultural do aluno.

Em contrapartida a facultatividade da Educação Física nos cursos noturnos indicava ainda algum resquício das concepções que orientavam as LDBs de 1961 e 1971.

$\mathrm{Na}$ intenção de modificar este quadro, segundo Silva e Venâncio (2005), em 01 de dezembro de 2003, a facultatividade foi alterada por meio da Lei $\mathrm{n}^{\circ}$ 10793, que determinou que as aulas de Educação Física passassem a ser facultativas não mais a todas as pessoas que estudassem no turno da noite, mas sim a todas que, independente do período em que estudassem, se enquadrassem em algumas condições previstas na lei que passou a conter a seguinte redação: 
Lei $n^{\circ} 10.793$, de $1^{\circ}$ de dezembro de 2003.

Altera a redação do art. 26, § 30, e o art. 92 da Lei 9294, de 20 de dezembro de 1996, que "estabelece as diretrizes e bases da educação nacional", e dá outras providências.

Art. 1ㅇ O § 3ำ do art. 26 da Lei nº 9.394, de 20 de dezembro de 1996, passa a vigorar com a seguinte redação:

"Art. 26

$\S 3^{\circ} \mathrm{A}$ educação física, integrada à proposta pedagógica da escola, é componente curricular obrigatório da educação básica, sendo sua prática facultativa ao aluno:

I - que cumpra jornada de trabalho igual ou superior a seis horas;

II - maior de trinta anos de idade;

III - que estiver prestando serviço militar inicial ou que, em situação similar, estiver obrigado à prática da educação física;

IV - amparado pelo Decreto-Lei no 1.044 , de 21 de outubro de 1969;

$\mathrm{V}-(\mathrm{VETADO})$

VI - que tenha prole.” (BRASIL, 2003).

Portanto, não é difícil concluirmos que apesar de suprimir a facultatividade da Educação Física nos cursos noturnos, a Lei 10.793 de 2003 representa um retrocesso de mais de 30 anos no que diz respeito aos pressupostos que respaldam os conhecimentos da área de Educação Física.

\section{Apontando caminhos: possibilidades de inclusão, apesar da facultatividade prevista na legislação}

Este estudo foi realizado em um colégio particular de um município do interior do Estado de São Paulo. Do ano 1997 até 2008, este pesquisador foi professor e coordenador de Educação Física do referido colégio, participando, portanto, de todo o processo de enfrentamento do problema instalado naquele colégio pelo constante aumento do número de solicitação de dispensas pelos alunos do Ensino Médio.

Em um levantamento realizado em 2005, foi verificado que os índices de dispensas nas aulas de Educação Física no Ensino Médio haviam atingido índices alarmantes (Tabela 1). Este quadro desencadeou nos professores de Educação Física do colégio um processo de busca por alternativas para o enfrentamento desta cultura que estava se instalando.

Tabela 1 - Total de alunos dispensados no Ensino Médio de 2000 a 2008.

\begin{tabular}{|c|c|c|c|}
\hline ANO & $\begin{array}{c}\text { Total de alunos do } \\
\text { Ensino Médio }\end{array}$ & $\begin{array}{c}\text { Alunos dispensados } \\
\text { da Educação Física }\end{array}$ & $\begin{array}{c}\text { Percentual de alunos } \\
\text { dispensados }\end{array}$ \\
\hline $\mathbf{2 0 0 0}$ & 260 & 95 & $36,53 \%$ \\
\hline $\mathbf{2 0 0 1}$ & 252 & 123 & $48,8 \%$ \\
\hline $\mathbf{2 0 0 2}$ & 259 & 115 & $44,4 \%$ \\
\hline $\mathbf{2 0 0 3}$ & 213 & 56 & $26,29 \%$ \\
\hline
\end{tabular}

(continua) 
(continuação)

\begin{tabular}{|c|c|c|c|}
\hline ANO & $\begin{array}{c}\text { Total de alunos do } \\
\text { Ensino Médio }\end{array}$ & $\begin{array}{c}\text { Alunos dispensados } \\
\text { da Educação Física }\end{array}$ & $\begin{array}{c}\text { Percentual de alunos } \\
\text { dispensados }\end{array}$ \\
\hline $\mathbf{2 0 0 4}$ & 167 & 56 & $33,53 \%$ \\
\hline $\mathbf{2 0 0 5}$ & 138 & 31 & $22,46 \%$ \\
\hline $\mathbf{2 0 0 6}$ & 166 & 29 & $17,46 \%$ \\
\hline $\mathbf{2 0 0 7}$ & 183 & 9 & $4,9 \%$ \\
\hline $\mathbf{2 0 0 8}$ & 184 & 5 & $2,7 \%$ \\
\hline
\end{tabular}

Como é possível verificar pela Tabela 1, entre os anos de 2000 e 2004 as dispensas estiveram entre um terço e metade dos alunos matriculados no Ensino Médio do colégio, sendo que no ano de 2001 este índice atingiu o seu auge com 48,8 \% dos alunos deste ciclo (123 alunos) dispensados das aulas de Educação Física.

Alguns fatores podem ser considerados determinantes para a cristalização desta "cultura das dispensas". Analisemos, portanto, aqueles que consideramos mais significativos:

a) aulas fora da grade: as aulas de Educação Física do Ensino Médio no colégio são oferecidas fora da grade horária dos demais componentes curriculares (as do Ensino Fundamental são na grade), o que dificulta o acesso dos alunos que precisam retornar à escola no período contrário, fazendo com que a Educação Física dispute espaço com as demais atividades extracurriculares exercidas por estes alunos, como cursos (informática, idiomas, reforço escolar etc.), atividades de lazer, esportes, ginástica/atividades de academia, trabalho, entre outros. Além disso, o fato de ser oferecida fora da grade horária atribui à Educação Física um status inferior às demais disciplinas que necessitam de maior tempo e espaço nesta matriz;

b) critérios e controle muito frágeis para a triagem das dispensas: os alunos eram dispensados com a simples apresentação dos atestados médicos ou de trabalho, sem uma triagem mais criteriosa por parte dos professores ou da equipe pedagógica do colégio, que tivesse como objetivo diagnosticar as verdadeiras causas das dispensas e avaliar as possibilidades de integrar estes alunos à disciplina. Um exemplo da fragilidade destes critérios refere-se às dispensas concedidas a alunos que apresentassem algum tipo de atestado médico. Nestes casos, além da lei não contemplar este tipo de dispensa, negligenciava-se a possibilidade de restringir a participação do aluno apenas a determinados conteúdos da Educação Física que lhe oferecessem algum tipo de risco à saúde;

c) inexistência de notas bimestrais para os alunos dispensados: os alunos dispensados das aulas de Educação Física não recebiam nenhum tipo de avaliação ou nota referente à disciplina, sendo registrado em seu boletim escolar apenas a letra “D”, que correspondia a dispensado, na coluna referente à Educação Física 
(os demais alunos recebiam notas de 0,0 a 10 pontos). Com isso, era como se a disciplina não existisse para estes alunos, não lhes causando nenhum tipo de ônus a sua não participação nas aulas;

d) propagação de uma cultura que era passada de "geração para geração", de que as dispensas eram "naturais": quando nos referimos à passagem de geração para geração, estamos fazendo uma alusão à perpetuação da cultura da dispensa dos alunos do Ensino Médio transmitindo para os alunos que vem do Ensino Fundamental quais seriam os caminhos para se obter a dispensa. Com isso, o sistema mostrava-se viciado, na medida em que o ciclo se renovava a cada ano, sustentado principalmente por uma conivência de todos os atores que participavam deste contexto, inclusive por nós, professores de Educação Física do colégio (o colégio contava com 4 professores de Educação Física).

É necessário fazermos a ressalva de que este quadro não é exclusividade deste colégio particular, pois na rede particular de ensino é muito mais comum que se possa imaginar a prática que permite aos alunos a obtenção de dispensas das aulas de Educação Física.

Dentre as práticas que tomamos conhecimento por meio de relatos de colegas, podemos destacar situações, não raras, em que colégios aceitam declarações de academias de ginástica, clubes ou escolinhas esportivas, como equivalência das aulas curriculares de Educação Física, dispensando, portanto, os alunos destas aulas. Outra situação, que também não é incomum nas escolas particulares, refere-se ao não oferecimento das aulas de Educação Física, principalmente no $3^{\circ}$ ano do Ensino Médio, com base no argumento de que nesta série os alunos precisam centrar todos os seus esforços na preparação para prestar os exames vestibulares.

A partir do ano de 2005, com o respaldo da equipe diretiva do colégio, passamos a analisar algumas possibilidades de coibir os pedidos de dispensas e, ao mesmo tempo, pensar em mecanismos que pudessem de alguma maneira incluir na esfera da cultura corporal do movimento aqueles alunos que realmente não pudessem participar das aulas.

A primeira medida adotada foi a de criar um sistema de avaliação paralela para os alunos que protocolassem algum tipo de dispensa. Os alunos, a partir de então, não mais seriam simplesmente dispensados das aulas de Educação Física sem qualquer tipo de nota ou avaliação. Foi criado um programa de avaliações por meio de trabalhos domiciliares que deveria ser cumprido por estes alunos e entregue ao final de cada bimestre. Esta estratégia, por si só, já refletiu em uma queda significativa no número de dispensas, passando de um percentual de 33,53\% no ano anterior para 22,46\% naquele ano de 2005.

Esta estratégia pode ser encarada como uma forma de "driblar" a legislação, na medida em que se configura em uma forma de tornar facultativa a presença nas aulas aos alunos que se enquadrem nos critérios previstos na lei, mas, por outro lado, obriga-os a se responsabilizarem por algum ônus por não participarem destas aulas e, ao mesmo tempo, permite que estes alunos tenham acesso a algum conhecimento da cultura corporal de movimento. 
Como foi a primeira tentativa de estabelecer algum parâmetro de avaliação para os alunos dispensados, esse programa sofreu algumas adaptações durante o ano, utilizando-se de trabalhos de pesquisa, relatórios de filme ${ }^{1}$ e relatórios de palestras ${ }^{2}$.

No ano seguinte, em 2006, foi adotada a mesma estratégia, sendo que o percentual de alunos dispensados já havia sofrido uma ligeira queda (de 22,46\% para 17,46\%), provavelmente em função do ônus que os alunos passaram a arcar ao solicitarem a dispensa das aulas. As avaliações realizadas naquele ano contaram com uma resenha crítica baseada em um texto que tratava da evolução histórica do futebol ${ }^{3}$, provas escritas baseadas em texto acadêmico ${ }^{4}$, em um conjunto de artigos do Dr. Dráuzio Varella ${ }^{5}$ e em uma palestra sobre a importância da atividade física na adolescência.

Talvez o ano de 2007 tenha sido o segundo divisor de águas em relação à campanha contra as dispensas nas aulas de Educação Física (o primeiro teria sido a criação do programa de avaliações, iniciado em 2005), pois a partir deste ano passamos a fazer uma interpretação mais fidedigna da alínea IV da Lei 10.793/2003. Segundo esta alínea, seriam dispensados das aulas de Educação Física os alunos amparados pelo Decreto-Lei no 1.044, de 21 de outubro de 1969, Decreto este que reza o seguinte:

\section{DECRETO-LEI No 1.044, DE 21 DE OUTUBRO DE 1969.}

Dispóe sobre tratamento excepcional para os alunos portadores das afeç̧ôes que indica.

Art $1^{\circ}$ São considerados merecedores de tratamento excepcional os alunos de qualquer nível de ensino, portadores de afecções congênitas ou adquiridas, infecções, traumatismo ou outras condições mórbitas, determinando distúrbios agudos ou agudizados, caracterizados por:

a) incapacidade física relativa, incompatível com a freqüência aos trabalhos escolares; desde que se verifique a conservação das condições intelectuais e emocionais necessárias para o prosseguimento da atividade escolar em novos moldes;

b) ocorrência isolada ou esporádica;

c) duração que não ultrapasse o máximo ainda admissível, em cada caso, para a continuidade do processo pedagógico de aprendizado, atendendo a que tais características se verificam, entre outros, em casos de síndromes hemorrágicos (tais como a hemofilia), asma, cartide, pericardites, afecções osteoarticulares submetidas a correções ortopédicas, nefropatias agudas ou subagudas, afecções reumáticas, etc.

Art $2^{\circ}$ Atribuir a êsses estudantes, como compensação da ausência às aulas, exercício domiciliares com acompanhamento da escola, sempre que compatíveis com o seu estado de saúde e as possibilidades do estabelecimento.

Art 3º Dependerá o regime de exceção neste Decreto-lei estabelecido, de laudo médico elaborado por autoridade oficial do sistema educacional.

1 O filme exibido foi o longa-metragem do gênero documentário intitulado Super size me: a dieta do palhaço, dirigido e protagonizado pelo cineasta estadunidense Morgan Spurlock.

2 Os temas das palestras foram respectivamente "O papel do exercício físico no controle do peso corporal e como auxiliar na terapia do diabetes mellitus e da hipertensão arterial" e "Capacidades físicas e esportes".

3 MÁXIMO, João. Memórias do futebol brasileiro. Estudos Avançados. v. 13, n. 37, São Paulo, set./dez., 1999. Disponível em: <http://www.scielo.br/pdf/ea/v13n37/v13n37a09. pdf > Acesso em 29/12/2008.

4 DAOLIO, Jocimar. A violência no futebol brasileiro. In: DAOLIO, Jocimar. Cultura: Educação Física e futebol. $2^{a}$ ed. Revisada e ampliada, Campinas-SP: Editora da Unicamp, 2003, p. 169-180.

5 VARELLA, Drauzio. Site Oficial Dr. Drauzio Varella - Artigos. Disponível em: $<\mathrm{http} / / /$ drauziovarella.ig.com.br/>. Acesso em: 29 dez. 2008. 
Art 4o Será da competência do Diretor do estabelecimento a autorização, à autoridade superior imediata, do regime de exceção.

Art 50 Êste Decreto-lei entrará em vigor na data de sua publicação, revogadas as disposições em contrário. (BRASIL, 1969)

Sem entrarmos em uma discussão mais aprofundada em relação ao teor desse decreto, gostaríamos apenas de atentar para o fato de que ele não se refere apenas à disciplina Educação Física, mas a todos os componentes curriculares. Além disso, as condições que assegurariam aos alunos as dispensas das aulas, bem como o direito à realização de trabalhos escolares domiciliares, dizem respeito a incapacidades físicas que impossibilitem a frequência às aulas. Desse modo, estes alunos estariam impossibilitados de frequentar tanto as aulas de Educação Física quanto as dos demais componentes curriculares.

Portanto, é preciso esclarecer que a partir de então foram estabelecidos dois mecanismos de tratamento do aluno com atestado médico, um para o aluno dispensado das aulas e outro para os alunos dispensados de determinadas atividades das aulas.

Os alunos dispensados das aulas de Educação Física por atestado médico seriam apenas aqueles incapacitados ou impossibilitados de frequentar a escola. Enquanto os alunos dispensados apenas das atividades seriam aqueles que, respaldados por um atestado médico, apresentassem algum tipo de limitação que implicasse risco para a saúde quando da prática de determinados movimentos. Nestes casos, os aluno deveriam frequentar as aulas, mas o professor iria poupá-lo das atividades contraindicadas, disponibilizando algum tipo de atividade alternativa, como relatório, leitura de texto, elaboração de redação, auxílio na regência das atividades etc.

Nesse sentido, a partir do ano de 2007 as dispensas das aulas de Educação Física respaldadas por atestados médicos passaram a obedecer uma análise mais criteriosa e o que foi possível perceber é que estes atestados diminuíram drasticamente de $17,46 \%$ para $4,9 \%$. Nesse ano também o rigor das avaliações passou a ser mais intenso, os alunos passaram a cumprir três etapas de avaliações que consistiam na entrega de um trabalho escrito, na sua apresentação para a própria classe em forma de seminário, durante as aulas de outras disciplinas que eram cedidas pelos professores, e na realização de uma prova escrita baseada no mesmo tema ${ }^{6}$.

Finalmente, no ano de 2008 chegou-se a um formato fechado de avaliações, segundo o qual os alunos passariam a cumprir no programa de avaliações as mesmas três etapas idealizadas em 2007, contudo, tendo sempre como base um artigo científico da área de Educação Física ${ }^{7}$, a partir do qual deveria ser elaborada uma resenha crítica como trabalho escrito.

6 Os temas utilizados neste ano foram: Capacidades físicas e suas relações com os esportes (10 bimestre); A questão do gênero nos esportes: entendendo as diferenças de desempenho entre homens e mulheres (2० bimestre); Por uma sociedade que respeite as diferenças ( $3^{\circ}$ bimestre) e, no $4^{\circ}$ bimestre, os alunos realizaram um relatório seguindo um roteiro pré-estabelecido, baseado no filme $O$ ano em que meus pais saíram de férias (direção: Cao Hambúrguer).

7 Os artigos utilizados no ano de 2008 foram respectivamente os seguintes:

MATA, Vilson Aparecido da. Da força física à estética corporal: as mudanças nas relações sociais retratadas no corpo. Revista da Educação Física/UEM. vol. 9, n. 1, p. 35-43, 1998. 
A partir desta última estratégia, pudemos observar que as avaliações tornaramse um pouco mais rigorosas, refletindo em um desempenho aquém do desejado por parte dos poucos alunos que fizeram parte do programa. $\mathrm{Na}$ realidade, as exigências não foram tão diferentes das exigências acadêmicas colocadas em prática pelas demais disciplinas, porém acreditamos que a cultura de que a Educação Física é uma "atividade" que não exige conhecimentos possa ter se configurado em um elemento decisivo para o baixo rendimento dos alunos.

A dificuldade em obter notas ao menos razoáveis na disciplina de Educação Física acabou resultando em um "maior empenho" por parte dos alunos em frequentar as aulas, pois todos perceberam que frequentar as duas aulas, que aconteciam uma vez por semana (aula dupla, portanto apenas 1 hora e 40 minutos de aula por semana), tornara-se "menos trabalhoso" que cumprir o programa de avaliações para alunos dispensados. Com isso, no ano de 2008, apenas 2,7\% dos alunos do Ensino Médio do colégio enquadravam-se na categoria de dispensados.

Cabe destacar que as aulas regulares de Educação Física não se restringiam à dimensão procedimental dos conteúdos (fazer desprovido de conceitos e atitudes). $\mathrm{Na}$ verdade, nestas aulas também eram exigidos trabalhos e realizadas avaliações sistematizadas, contudo estes trabalhos e avaliações, em geral, eram realizados em grupos e envolviam leituras e discussões sobre os temas abordados, tornando-os mais significativos aos alunos. Além disso, os alunos que frequentavam as aulas regulares eram avaliados de uma forma mais processual e global.

\section{Considerações finais}

Acreditamos que seja necessário refletir e discutir, respaldados por argumentos sólidos, a necessidade de uma organização curricular em Educação Física que aponte para a construção de uma identidade escolar. Este processo envolveria a discussão sobre quais conteúdos seriam mais relevantes e qual a abordagem mais significativa para estes conteúdos em cada nível de ensino, sobre como estes conteúdos se articulariam entre si e com o projeto pedagógico da unidade escolar e do sistema de ensino de uma maneira geral, revestindo a Educação Física de uma identidade pedagógica institucional.

Assim, a Educação Física poderia assumir efetivamente o status de componente curricular, como prevê a legislação brasileira, cumprindo sua parcela do papel destinado à escola, que, segundo González (2006), consiste em introduzir os alunos no mundo sociocultural, incluindo-os no projeto renovado de (re)construção deste mundo.

Gostaríamos de deixar claro que este estudo de caso não tem a pretensão de estabelecer algum tipo de solução para o problema das dispensas das aulas de Educação Física, tampouco objetiva estabelecer algum tipo de modelo ou receita para coibir tais situações. Mesmo porque, é preciso levar em consideração que para cada realidade será necessário um tipo de medida que atenda melhor às necessidades do contexto em questão.

PALMA, Alexandre. Atividade física, no processo saúde-doença e condições sócio-econômicas: uma revisão de literatura. Revista Paulista de Educação Física, São Paulo, vol. 14, n. 1, p. 97-106, jan./jun., 2000.

RUBIO, Kátia; CARVALHO, Adriano L. Areté, fair play e o movimento olímpico contemporâneo. Revista Portuguesa de Ciências do Desporto. vol. 5, n. 3, p. 350-357, set. 2005.

VAZ, Alexandre Fernandez. Doping, esporte, performance: notas sobre os 'limites' do corpo. Revista Brasileira de Ciências do Esporte. Campinas-SP, v. 27, n. 1, , p. 23-36set., 2005. 
Aliás, não podemos deixar de esclarecer que os resultados deste estudo só foram possíveis em virtude do apoio da equipe diretiva do colégio que, principalmente na figura do coordenador pedagógico do Ensino Médio, sempre forneceu todo o respaldo necessário para que estas ações se efetivassem. Sem este apoio, obviamente tudo seria mais difícil, mas nem por isso deveríamos cruzar os braços e nos conformar com a situação.

Nosso intuito aqui foi o de analisar um caso particular que envolve pelo menos 5 anos de luta contra a cultura das dispensas nas aulas de Educação Física no Ensino Médio, que apresentaram resultados bem sucedidos tanto no sentido de criar um mecanismo dotado de rigor suficiente para não encorajar os alunos a forjarem pedidos de dispensa injustificados, como na tentativa de possibilitar de alguma maneira a inclusão na esfera da cultura corporal de movimento, daqueles alunos impossibilitados de frequentar as aulas de Educação Física.

Sabemos que uma das primeiras condições para garantir a não exclusão dos alunos das aulas de Educação Física por meio das dispensas consiste na melhoria da qualidade destas aulas que não podem continuar a ser uma simples repetição dos processos de iniciação esportiva vivenciados pelos alunos durante o Ensino Fundamental, tampouco o simples "rola bola" sem intervenção do professor, já criticados por diversos autores como Darido e Sanches Neto (2005), Darido e Souza Júnior (2007), entre outros.

Esta melhoria da qualidade das aulas, no nosso entendimento, deveria prever a diversificação e o aprofundamento de estratégias e conteúdos, já propostos por diversos autores. Porém, é preciso esclarecer que o contexto que envolve a questão das dispensas nas aulas de Educação Física é muito mais amplo e, provavelmente, um dos fatores determinantes para a ocorrência destas dispensas esteja relacionado ao baixo status da disciplina, diretamente ligado à sua disposição fora da grade horária curricular regular.

Inclusive, nos arriscaríamos a dizer que qualquer que fosse a disciplina que se oferecesse no período contrário correria o risco de ter um alto percentual de dispensas, com a única ressalva feita ao caráter funcionalista vinculado a elas, que poderia inibir este mecanismo em função da pressão, principalmente de pais, para que os alunos frequentassem as aulas para obter bons resultados nos exames vestibulares.

Por fim, diríamos que as dispensas das aulas de Educação Física representam uma prática que caminha no sentido contrário à valorização do status que a LDB-96 conferiu à área ao classificá-la como componente curricular da Educação Básica, contramão esta legitimada por um dispositivo resgatado pela mesma legislação em 2003. Contudo, como ficou demonstrado por este estudo de caso, é plenamente possível a adoção de estratégias que viabilizem a valorização do "componente curricular" e a superação da "facultatividade".

Attendance exemption in physical education classes:

Showing the way to minimize the effects of an archaic legislation

Abstract

This research study is based on a case study conducted at a private school and aims at presenting a proposal which points to alternative ways to lead with the legal device that legitimize attendance exemption in physical education classes. Results show that the adoption of an examination program applied to 
exempt students, together with other measures, have proved effective towards lowering the number of exempt requests. Data shows that exempts reached $48.8 \%$ of the total number of high school students in the researched institution, but dropped to $2.7 \%$ after the examination program was adopted. Despite the existing exempt legislation, this study has shown that it is possible to build mechanisms that can minimize attendance exemption in physical education classes.

Keywords: Physical Education - School - Attendance Exemption - Legislation

Dispensas de cursar las clases de Educación Física: presentando caminos para disminuir los efectos de la arcaica legislación

\section{Resumen}

O fenômeno sociocultural das torcidas de futebol no Brasil é um assunto privilegiado nos debates atuais sobre o esporte. Contudo, ainda há carência de pesquisas que focalizem as torcidas dos clubes de futebol do ponto de vista histórico. Na perspectiva da história cultural, o presente estudo tem como objetivo identificar quais as formas de manifestação da torcida do Grêmio Esportivo Renner de 1945 até 1959. Para tanto, foram coletadas fontes impressas, as quais foram submetidas à análise documental, destacando-se como principais os boletins produzidos pelas empresas Renner, um filme documentário sobre o time e um estudo monográfico sobre o clube. Dados apontam o Renner como um dos clubes pioneiros no processo de formação de torcidas organizadas no Brasil.

Palabras clave: Educación Física - Escuela - Dispensas - Legislación

\section{Referências}

BRASIL. Lei n. 9.131, de 20 de dezembro de 1961. Fixa as diretrizes e bases da educação nacional. Presidência da República - Casa Civil - Subchefia de Assuntos Jurídicos, Brasília, DF, 1961. Disponível em: <http://www.planalto.gov.br/ccivil/Leis/L4024. htm> Acesso em: 04 jun. 2009.

BRASIL. Lei n. 5.692, de 11 de agosto de 1971. Fixa diretrizes e bases para o ensino de $1^{\circ}$ e $2^{\circ}$ graus, e dá outras providências. Presidência da República-Casa Civil-Subchefia de Assuntos Jurídicos, Brasília, DF, 1971. Disponível em: <http://www.planalto. gov.br/CCIVIL/LEIS/L5692.htm> Acesso em: 04 jun. 2009.

BRASIL. Ministério de Educação. Decreto-Lei no 1.044, de 21 de outubro de 1969. Dispõe sobre tratamento excepcional para os alunos portadores das afecções que indica. Presidência da República - Casa Civil - Subchefia de Assuntos Jurídicos, Brasília, DF, 1969. Disponível em: <http://www.planalto.gov.br/ccivil_03/decreto-lei/ Del1044.htm> Acesso em: 29 dez. 2008.

BRASIL. Lei n. 9.394, de 20 de dezembro de 1996. Estabelece as diretrizes e bases da educação nacional. Presidência da República - Casa Civil - Subchefia de Assuntos Jurídicos, Brasília, DF, 1996. Disponível em: <http://www.planalto.gov.br/ccivil/Leis/ L9394.htm\#art92> Acesso em: 04 jun. 2009.

BRASIL. Ministério da Educação. Lei no 10.793, de $1^{\circ}$ de dezembro de 2003. A1tera a redação do art. 26, § 30, e o art. 92 da Lei 9294, de 20 de dezembro de 1996, que "estabelece as diretrizes e bases da educação nacional", e dá outras providências. Presidência da República - Casa Civil - Subchefia de Assuntos Jurídicos, Brasília, DF, 2003. Disponível em: <http://www.planalto.gov.br/ccivil_03/leis/2003/L10.793. htm> Acesso em: 27 dez. 2008. 
CASTELLANI FILHO, Lino. Os impactos da reforma educacional na educação física brasileira. Revista Brasileira de Ciências do Esporte. vol. 19, n. 01, p. 20-33, set. 1997.

DARIDO, Suraya Cristina; SANCHES NETO, Luiz. O contexto da educação física na escola. IN: DARIDO, Suraya Cristina; RANGEL, Irene Conceição Andrade (coord). Educação física na escola: implicações para a prática pedagógica. Rio de Janeiro: Guanabara Koogan, 2005. p. 50-61. (Coleção Educação Física no Ensino Superior).

DARIDO, Suraya Cristina; SOUZA JÚNIOR, Osmar Moreira de. Para ensinar educação física: possibilidades de intervenção na escola. Campinas-SP: Papirus, 2007.

GONZÁLEZ, Fernando Jaime. Projeto curricular e educação física: o esporte como conteúdo escolar. In: REZER, Ricardo (org.). O fenômeno esportivo: ensaios críticoreflexivos. Chapecó: Argos, 2006. p. 69-109.

LÜDKE, Menga; ANDRÉ, Marli, E. D. A. Pesquisa em educação: abordagens qualitativas. São Paulo: EPU, 1986. (Temas básicos de educação e ensino)

SILVA, Eduardo Vinícius Mota e; VENÂNCIO, Luciana. Aspectos legais da educação física e integração à proposta pedagógica da escola. IN: DARIDO, Suraya Cristina; RANGEL, Irene Conceição Andrade (coord). Educação física na escola: implicações para a prática pedagógica. Rio de Janeiro: Guanabara Koogan, 2005. p. 50-61. (Coleção Educação Física no Ensino Superior).

SOUZA JÚNIOR, Marcílio. O saber e o fazer pedagógicos da educação física na cultura escolar: o que é um componente curricular. In: CAPARROZ, F. E. (org.) Educação física escolar: política, educação e intervenção. Vitória: Proteoria, 2001.

TARDIF, Maurice; LESSARD, Claude. O trabalho docente: elementos para uma teoria da docência como profissão de interações humanas. 3 ed. Petrópolis, RJ: Vozes, 2007.

Recebido em: 09 de março de 2009

Revisado em: 12 de maio de 2009

Aprovado em: 18 de maio de 2009

\section{Endereço para correspondência}

Osmar Moreira de Souza Júnior

Universidade Federal de São Carlos

Rodovia Washington Luís, km 235

Bairro: Monjolinho

São Carlos-SP

CEP: $13.565-905$ 